\title{
Comparison of Selection Indices in the Selection of Malting Barley Genotypes Irrigated
}

\section{Ricardo Meneses Sayd ${ }^{1 *}$, Renato Fernando Amabile ${ }^{2}$, Fábio Gelape Faleiro ${ }^{2}$, Ana Paula Leite Montalvão ${ }^{3}$ and Mateus Costa Coelho ${ }^{1}$}

${ }^{1}$ Faculdade de Agronomia e Medicina Veterinária da Universidade de Brasília, Brasília, DF, Brasil

${ }^{2}$ Embrapa Cerrados, Planaltina, DF, Brasil

${ }^{3}$ Universitat Politécnica de Valencia, Institute of Mediterranean Agroforestry, Valencia, Espanha

*Corresponding Author: Ricardo Meneses Sayd, Faculdade de Agronomia e Medicina Veterinária da Universidade de Brasília, Brasília, DF, Brasil.

Received: July 02, 2019; Published: August 14, 2019

DOI: 10.31080/ASAG.2019.03.0611

\begin{abstract}
The purpose of this work was to compare selection indices, in five environments, two sites, in 3 years, among 69 barley genotypes. Three characters were used in the selection: Estimated grain yield - Yield; Kernel plumpness - KP; Degree of lodging - LOD. The selection indices used were Weight-free and Parameter-free index, Desired Genetic Gain index, Rank Sum and Genotype-Ideotype Distance index. The Weight-free and Parameter-free and Desired Genetic Gain indices obtained higher selection gains for the characters KP, LOD, and Yield, respectively; however, they did not select genotypes with significant gains for the other characters. The Rank Sum and Genotype-Ideotype indices selected genotypes with intermediate gains for the three characters of interest. The Weight-free and Parameter-free and Desired Genetic Gain indices were not adequate to simultaneously select the three characters of interest for barley. The Rank Sum and Genotype-Ideotype selection indices were considered more interesting for simultaneous selection due to the selection gains of a satisfactory magnitude for the three characters of interest. Based on the selection of genotypes for each index within the environments, it was more efficient to select the most stable materials, since they obtained a higher frequency of selection among the other indices.
\end{abstract}

Keywords: Selection Gain; Coincidence Index; Plant Breeding; Hordeum vulgare L.

\section{Introduction}

The selection of superior genotypes is highly complex since the agronomic characters of greater economic importance are of a quantitative nature and correlated with each other [1]. Promising genotypes should simultaneously bring together several favorable attributes to raise yield and meet market requirements [2]. In malting barley, besides the importance of grain yield, grain size and uniformity (kernel plumpness) have a great influence on the quality of the final product [3]. However, the selection of superior progenies is, in general, made difficult by the fact that the charac- ters of agronomic importance, in the majority, have low heritability and correlation among themselves [2].

Linking high yields to high kernel plumpness is not a simple task; the low genotypic and phenotypic correlation between these characters [4-7] reduces the efficiency of the work of the breeder, especially when it is intended to use indirect selection. The simultaneous selection of a character set of economic importance increases the chance of success of a breeding program [8]. Thus, the selection indices constitute multivariate techniques that associate 
the information related to several characters of agronomic interest with the genetic properties of the evaluated population. With the selection indices, numerical values are created, which function as an additional theoretical characteristic, resulting from the combination of certain characteristics selected by the breeder, on which one wishes to maintain simultaneous selection [9]. Different indices represent different selection alternatives in breeding programs, and consequently different percentage gains.

There are several options for selection indices in the literature. The first index was proposed by Smith [10] and Hazel [11], it is a parametric index in which the matrices of genotypic and phenotypic variance and covariance are used, also counting on the ability of the breeder to define the economic weights for each character.

Another index based on genetic parameters was proposed by Pesek and Baker [12], named "desired genetic gains" of individual characters. This index was proposed without the need to assign relative economic weights in the calculation of the selection indices. The obtained index will result in a maximum gain for each character, according to the relative importance assumed by the breeder in the definition of the desired gain, with the limitation imposed by the phenotypic and genotypic constitution of the population.

There are non-parametric indices where there is no need to use the variance and covariance matrices to obtain the selection indices.

The index proposed by Elston [13] can be applied both in the initial and final stages of breeding program, for it allows the establishment of critical values, below which the genotypes are discarded. The multiplicative index makes it possible to select approximately the same genotypes as the linear index would, with the advantage of dismissing the assignment of weights to the characters and estimates of variances and covariates, which makes its application easier, in relation to the linear or parametric indices [14].

Another non-parametric index, the rank sum, proposed by Mulamba and Mock [15], consists in classifying the genotypes in relation to each of the characters, in order favorable to breeding (ranks), by assigning higher absolute values to those of better performance. Then, the values assigned to each character are summed to obtain the rank sum that shows the classification of the genotypes [8].
The genotype-ideotype index [16], non-parametric, is obtained from the adjusted phenotypic means and the Euclidean distances of each individual to an ideal genotype. These indices are later standardized and weighted by the weights assigned to each character. It is also possible to define optimal values as well as the ideal minimum value for selecting each character.

Using these tools and with the aim of selecting the most promising genotypes to be used in crossing blocks or even with cultivars, aiming at genotypes with characteristics of high yield, industrial quality and with agronomic benefits to the farmer, the objective of this work was to compare the Combined Selection performed by the breeder with the gains and selection coincidence of each index used in the different environments.

\section{Material and Methods}

The selection was based on five experiments, conducted for three years and in two sites under irrigation in Distrito Federal. The sites are: Experimental Field of Embrapa Cerrados (CPAC),

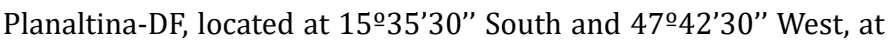
an altitude of 1,007 m, on a RED OXISOL Dystrophic typical, clayey; and Experimental Field of Embrapa Products and Market (SPM), in Recanto das Emas-DF, at $15^{\circ} 54^{\prime}$ '53" South and 48 $02^{\prime} 14^{\prime \prime}$ West, at an altitude of 1,254 m, on a RED OXISOL Dystrophic typical, clayey. The trials were named as AMB1 (CPAC in 2012), AMB2 (CPAC in 2013), AMB3 (CPAC in 2014), AMB4 (SPM in 2013), and AMB5 (SPM in 2014).

A total of 69 barley genotypes were evaluated (Table 1), using a randomized complete block design with three replicates. The plots were six rows of five meters long, spaced $20 \mathrm{~cm}$ apart, with a usable floor area of 4.8 sq. $\mathrm{m}$ for each plot, with a density of 300 plants per sq. m. Three characters were used in the selection: 1 . Estimated grain yield (kg.ha-1) - Yield; 2. Kernel plumpness (>2,5 $\mathrm{mm}$ ) (\%) - KP; 3. Degree of lodging (\%) - LOD (lodging value equal to zero means minimal or nonexistent lodging, and conversely, when equal to 100 , lodging is maximum). Other three characters were used were used only to observe the indirect selection gains: Thousand seeds weight (TSW), Plant height (Height), and Days to heading (Cycle). 


\begin{tabular}{|c|c|c|c|c|c|c|}
\hline & Genotype & Yield & Class1 & LOD & Origin & NGR \\
\hline 1 & CI 13824 ATLAS 68 & 5049.5 & 69.9 & 62.7 & USA & 6 \\
\hline 2 & CI 10022 & 5662.4 & 65.6 & 97.7 & Colombia & 6 \\
\hline 3 & CI 13711 & 5106.6 & 72.5 & 34.3 & Colombia & 6 \\
\hline 4 & CI 10071 WOLFE & 5012.7 & 76.1 & 23.0 & Canada & 6 \\
\hline $5^{*}$ & MCU 3870 PI 402348 & 5594.3 & 79.4 & 46.3 & Colombia & 6 \\
\hline $6^{*}$ & MCU 3502 PI 401980 & 5286.7 & 85.5 & 17.3 & Colombia & 6 \\
\hline 7 & CI 12068 MAZOWIECKI & 5114.5 & 64.0 & 32.7 & Poland & 6 \\
\hline 8 & MCU 3654 PI 402132 & 5732.5 & 79.9 & 63.0 & Colombia & 6 \\
\hline $9^{*}$ & MCU 3449 PI 401927 & 6184.9 & 73.8 & 40.3 & Colombia & 6 \\
\hline 10 & CI 06244 & 5385.1 & 76.0 & 75.7 & USA & 6 \\
\hline $11^{*}$ & CI 09952 & 5417.3 & 81.0 & 43.7 & Russia & 6 \\
\hline $12 *$ & MCU 3884 PI 402362 & 5285.5 & 77.9 & 43.3 & Colombia & 6 \\
\hline $13^{*}$ & MCU 3852 PI 402330 & 5536.1 & 74.9 & 24.0 & Colombia & 6 \\
\hline 14 & CI 12367 BRANISOVICKY & 5034.7 & 78.3 & 23.5 & Czech Republic & 2 \\
\hline $15^{*}$ & MCU 3865 PI 402343 & 5694.5 & 78.8 & 30.7 & Colombia & 6 \\
\hline 16 & CARINA PI 371632 & 4704.1 & 76.7 & 21.3 & Germany & 2 \\
\hline $17^{*}$ & MCU 3634 PI 402112 & 6109.0 & 83.5 & 34.3 & Colombia & 6 \\
\hline 18 & CI 12918 & 5642.1 & 77.1 & 92.3 & Ethiopia & 6 \\
\hline $19 *$ & MCU 3750 PI 402228 & 5151.7 & 78.8 & 25.0 & Colombia & 6 \\
\hline 20 & CI 15323 2222-79 & 4840.5 & 65.2 & 96.7 & Tunisia & 6 \\
\hline 21 & MCU 3878 PI 402356 & 5824.3 & 70.6 & 25.3 & Colombia & 6 \\
\hline 22 & CI 09962 & 4413.5 & 79.0 & 49.0 & Iran & 6 \\
\hline 23 & MCU 3478 PI 401956 & 5675.1 & 68.0 & 53.3 & Colombia & 6 \\
\hline 24 & CI 06109 VELVON & 4407.7 & 68.3 & 64.7 & USA & 6 \\
\hline 25 & CI 14041 & 4524.3 & 73.0 & 41.7 & Ethiopia & 6 \\
\hline 26 & CI 07772 & 5419.4 & 67.9 & 74.7 & India & 6 \\
\hline 27 & CI 15580 QB 136-41 & 6020.7 & 70.8 & 56.3 & Canada & 6 \\
\hline 28 & MCU 3454 PI 401932 & 5138.0 & 69.0 & 43.0 & Colombia & 6 \\
\hline 29 & CI $152792528-23$ & 4856.3 & 59.6 & 77.0 & Tunisia & 6 \\
\hline 30 & CI 10017 RASPA COMUN 1085 & 4799.6 & 58.3 & 92.7 & Colombia & 6 \\
\hline 31 & CI 14031 & 4800.8 & 59.9 & 29.7 & Ethiopia & 6 \\
\hline $32^{*}$ & MCU 3484 PI 401962 & 5123.7 & 76.0 & 21.7 & Colombia & 6 \\
\hline $33^{*}$ & MCU 3461 PI 401939 & 5385.6 & 77.3 & 36.0 & Colombia & 6 \\
\hline 34 & CI 09961 & 5298.9 & 76.5 & 64.3 & Iran & 6 \\
\hline 35 & CI 14925 ELS 6402-512 & 5225.7 & 60.5 & 64.7 & Ethiopia & 6 \\
\hline $36^{*}$ & CI 15565 QB 136-20 & 5325.4 & 78.7 & 39.7 & Canada & 6 \\
\hline 37 & CI 11493 FRUGHERSTE STANKAS & 4688.3 & 78.7 & 25.0 & Germany & 2 \\
\hline 38 & CI 10078 ATLAS 57 & 4907.7 & 80.9 & 24.0 & USA & 6 \\
\hline
\end{tabular}




\begin{tabular}{|l|l|c|c|c|c|c|}
\hline 39 & MCU 3556 PI 402034 & 4958.7 & 68.9 & 21.3 & Colombia & 6 \\
\hline 40 & CI 15591 QB 139-1 & 5926.4 & 74.3 & 70.0 & Canada & 6 \\
\hline 41 & CI 06946 & 4596.6 & 45.2 & 89.3 & Iran & 6 \\
\hline $42^{*}$ & CI 13715 & 5621.1 & 73.4 & 31.3 & Colombia & 6 \\
\hline 43 & MCU 3816 PI 402294 & 5369.0 & 80.7 & 53.3 & Colombia & 6 \\
\hline $44^{*}$ & MCU 3851 PI 402329 & 6009.1 & 78.9 & 43.7 & Colombia & 6 \\
\hline $45^{*}$ & MCU 3469 PI 401947 & 6150.3 & 79.9 & 22.0 & Colombia & 6 \\
\hline 46 & CI 09958 & 5319.7 & 85.2 & 33.0 & Morocco & 6 \\
\hline 47 & MCU 3827 PI 402305 & 4636.9 & 83.9 & 41.3 & Colombia & 6 \\
\hline 48 & CI 13894 & 4984.7 & 58.9 & 32.7 & USA & 6 \\
\hline 49 & CI 10501 ATHENAIS S-50-34 & 4529.0 & 75.9 & 87.3 & Cyprus & 6 \\
\hline 50 & CI 09959 & 4970.2 & 82.3 & 22.0 & Morocco & 6 \\
\hline 51 & CI 15560 QB 136-4-1 & 5835.0 & 67.1 & 84.0 & Canada & 6 \\
\hline $52^{*}$ & MCU 3489 PI 401967 & 5275.0 & 78.3 & 32.7 & Colombia & 6 \\
\hline 53 & CI 06188 & 4998.3 & 56.1 & 91.7 & Mexico & 6 \\
\hline 54 & MCU 3653 PI 402131 & 4785.8 & 76.1 & 42.3 & Colombia & 6 \\
\hline 55 & CI 12920 & 5402.8 & 66.8 & 77.0 & Ethiopia & 6 \\
\hline 56 & CI 13683 NUMAR & 6039.0 & 49.4 & 42.0 & USA & 6 \\
\hline 57 & MCU 3719 PI 402197 & 4253.6 & 78.4 & 38.0 & Colombia & 6 \\
\hline 58 & MCU 3858 PI 402336 & 4561.1 & 73.4 & 36.0 & Colombia & 6 \\
\hline 59 & MCU 3883 PI 402361 & 5454.5 & 58.3 & 31.3 & Colombia & 6 \\
\hline 60 & GALOVER (C A N 1126) PI 361636 & 5130.8 & 59.8 & 34.0 & Denmark & 2 and 6 \\
\hline 61 & CI 10018 RASPA PRECOZ 604 & 5422.1 & 67.1 & 88.3 & Colombia & 6 \\
\hline $62^{*}$ & MCU 3571 PI 402049 & 5422.9 & 81.6 & 44.0 & Colombia & 6 \\
\hline 63 & MCU 3721 PI 402199 & 4681.9 & 72.3 & 12.7 & Colombia & 6 \\
\hline 64 & E 3/416 PI 356495 & 5653.0 & 52.8 & 69.3 & Ethiopia & 6 \\
\hline 65 & H HOR 2325/58 PI 329126 & 5846.4 & 52.9 & 22.0 & Afghanistan & 6 \\
\hline $66^{*}$ & MCU 3452 PI 401930 & 5311.5 & 73.1 & 27.3 & Colombia & 6 \\
\hline $67^{*}$ & MCU 3832 PI 402310 & 5758.7 & 69.6 & 20.0 & Colombia & 6 \\
\hline $68^{*}$ & MCU 3592 PI 402070 & 5506.3 & 71.5 & 34.0 & Colombia & 6 \\
\hline $69^{*}$ & BRS 180 & 6688.1 & 79.9 & 5.3 & Brazil & 6 \\
\hline & & & & & \\
\hline
\end{tabular}

Table 1: Mean of the five environments for estimated grain yield (Yield), kernel plumpness (>2.5 mm) (Class1), and lodging (LOD) and country of origin (Origin) and number of grain rows per ear (NGR)

*Genotypes selected through Combined Selection.

The characters used in the selection Yield and KP were evaluated in the sense of character addition, while LOD was selected for character decrease, for it is a detrimental character to the harvest and the quality of the grains.
The method used in the Combined Selection (CS) was the combination of the rank sum selection modified index [15] based only on the character estimated grain yield in the five environments, with the weight-free and parameter-free index of Elston [13], se- 
lecting only genotypes with more than $70 \%$ for KP and less than $30 \%$ for LOD, in at least 3 of the 5 trials.

The Combined Selection was compared with four classic selection indices in each environment: Weight-free and Parameter-free index [13], Desired Genetic Gain index [12], Rank Sum [15], and Genotype-Ideotype Distance index [16].

For the weight-free and parameter-free index of Elston, values were standardized so that at least 21 genotypes were selected in each trial. For estimated grain yield, genotypes above 4,000 kg.ha-1 were selected, with kernel plumpness ( $>2,5 \mathrm{~mm}$ ) higher than $64 \%$ and with lodging degree below de $77 \%$.

In the Pesek and Baker Index, gains were defined based on the genotypic standard deviation. For the Yield character, due to its greater importance, it was attributed double the genotypic standard deviation. The desired gain for the KP and LOD characters was the genotypic standard deviation.

The Mulamba and Mock index [15] hierarchizes genotypes, initially, for each character, by assigning higher absolute values to those of better performance. The economic weights were arbitrarily defined by the breeder by attempt, and the proportion found to be ideal for the characters Yield, KP and LOD was of 5, 3, 3 respectively.

The Genotype-Ideotype Distance index (GIDI), non-parametric, is obtained from the adjusted phenotypic means and the Euclidean distances of each individual to an ideal genotype. The values of the ideotype are different for each trial, and the maximum or minimum value of each characteristic is defined as ideal. Also, the desirable minimum values for each characteristic were arbitrarily defined by the breeder (Yield $=4,000 \mathrm{~kg} \cdot \mathrm{ha}^{-1}, \mathrm{KP}=60.0 \%$ and LOD $=50.0 \%$ ). The economic weights defined were the same as those used for "rank sum", which are 5 for Yield and 3 for KP and LOD.

The GENES software [16] was used to perform the statistical analyses.

For each selection index in each trial the coincidence index was obtained (number of selected genotypes that coincide with CS divided by the total number of selected genotypes). The average coincidence indices were obtained, as the mean of the coincidence for each index and for each test.
The frequency at which each genotype was selected by each index was also obtained. From this frequency a frequency plot was generated.

\section{Results and Discussion}

Comparison of selection indices between environments

The comparison of the selection gains between the selection indices was performed for each experimental environment and selecting 21 genotypes among the 69, that is, with a $30 \%$ selection intensity.

In the AMB1, CPAC 2012, the selection index that proportioned the highest selection gain (\%) for the Yield character was the desired genetic gain index (PB) with $25.4 \%$, followed by the indices of Mulamba and Mock (MM) with 19.2\%, Ideotype-genotype (IG) with $18.0 \%$, and Elston (14.2\%) (Table 2). The gains for Yield were considered high for all the indices when compared to the other environments. However, the PB index, despite allowing high gain for Yield, presented the lowest SG for KP (3.94\%), that is, it selected genotypes with low industrial quality. The indices of Elston and MM allowed SG of 13\%, while the IG index brought an increase of $11.28 \%$ for this character.

The third character of interest for the selection was lodging (LOD). Among the indices, the one of Elston presented the highest absolute gain, which was $-83.81 \%$. The selection for this character is intended to eliminate lodging, which promotes higher harvest efficiency and higher quality and sanity of the kernels. The indices IG $(-65.2 \%)$ and MM (-38.7\%) also presented desirable gains selecting genotypes with a lower LOD level. The PB index proportioned SG of $14.0 \%$ (Table 2), the only that, despite selecting more productive genotypes, presented an increase in the level of LOD.

The indirect selection caused negative gains for Cycle, varying from $-5 \%$ to $-6 \%$ for all indices (Table 2 ). These gains are considered to be desirable since they have led to the selection of earlier genotypes, which is an advantage in the irrigated production system of the savanna.

The heritability in broad sense was greater than $90 \%$ for all characters in AMB1, factor that favors the direct selection for each character (Table 2). Heritability values above 90\% for the agronomic characters Yield and KP were also reported by Amabile., et $a l$, reporting low $\mathrm{h}^{2}$ for LOD (42\%). 


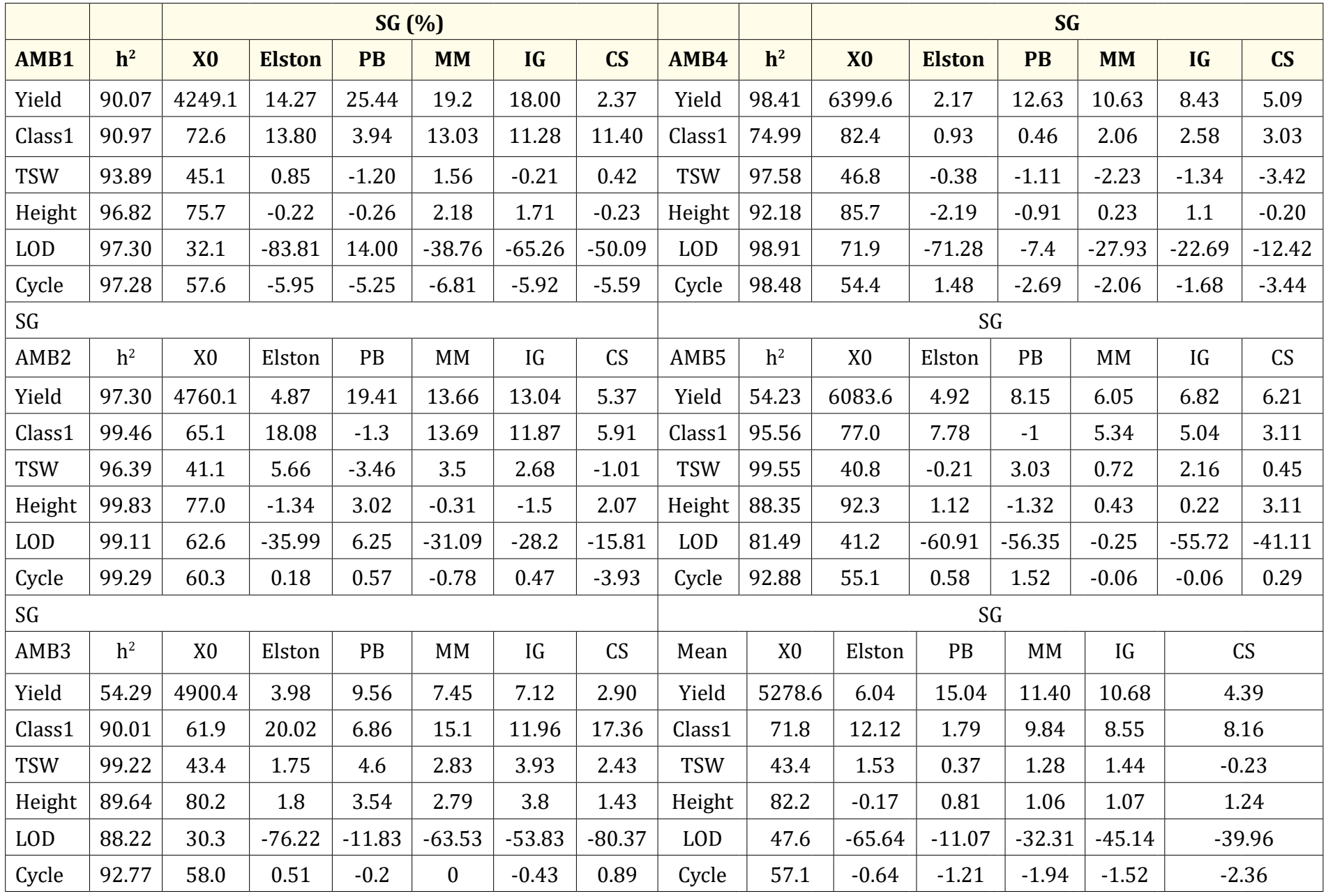

Table 2: Estimates of gain with selection (SG\%), heritability in broad sense $\left(\mathrm{h}^{2}\right)$ and mean of the 69 genotypes (X0) obtained for five characters through five selection indices in five environments for 69 genotypes of barley in Distrito Federal, in the agricultural years 2012/2013/2014.

*Elston: Elston Index (1963); PB: Pesek and Baker Index (1969); MM: Mulamba and Mock Index (1978); IG: Ideotype-genotype distance Index (2006); CS: Combined Selection **Yield: estimated grain yield (kg.ha-1); Class1: kernel plumpness (>2.5 mm) (\%); TSW: weight of a thousand seeds (g); Height: height of the plants (cm); LOD: plant lodging (\%); Cycle: days to heading (days)

In AMB2, CPAC 2013, despite the higher values for broad heritability, the SG (\%) for Yield and LOD were lower than the ones obtained in AMB1. This demonstrates the difference of genotypic behavior in relation to the change of agricultural year.

As in AMB1, in AMB2 the PB index was the one that proportioned the highest gain for Yield, with $19.41 \%$. The indices MM and IG presented SG of $13 \%$, followed by the Elston index with $4.8 \%$. For KP, the SG were satisfactory for the genotypes selected by the indices of
Elston (18.0\%), MM (13.6\%), and IG (11.8\%). On the other hand, the gain was negative for the PB index $(-1.3 \%)$, which results in genotypes with smaller kernels and consequently lower extract content, which generates financial losses for the brewing industry.

As in AMB1, in AMB2 the Elston index ( $\mathrm{SG}=-35.9 \%$ ) was more interesting for LOD, but with gains close to those made possible by the MM (-31.0\%) and IG $(-28,2 \%)$ indices. The genotypes selected by the PB index showed a $6.2 \%$ increase in LOD (Table 2). 
Contrary to the high heritabilities of environments 1 and 2, in AMB3 (CPAC 2014) h2 for Yield was 52.2\%. This low value of $h^{2}$ contributed to the SG for Yield being considerably lower than in the other environments. Selection gains were $9.5 \%$ in the genotypes selected by the PB index, 7.4\% for MM, 7.1\% for IG, and 3.9\% for the Elston index (Table 2).

In AMB3, for the character KP, the Elston index $(20,0 \%)$ presented higher SG (\%) when compared to all the other environments and selection indices. The other indices proportioned positive gains of $15.1 \%$ for MM, $11.9 \%$ for IG, and $6.8 \%$ for PB (Table 2).

Genotypes with high selection gains for LOD (at least -50.0\%) were selected through the selection indices, except when using the PB index (-11.8\%). As in the other environments, the Elston index $(-76.2 \%)$ was the one that presented the genotypes with highest gain for this character (Table 2).

Analyzing the other characteristics not used in the selection, the genotypes selected by all the indices showed an increase in relation to the average of the genotypes, varying from $1.8 \%$ to $3.8 \%$ for Height and from $1.75 \%$ to $4.6 \%$ for TSW. For the Cycle character, there was no increase above $1 \%$ (Table 2).

In AMB4, SPM 2013, the selection gains were lower than the ones of the genotypes selected in AMB2, CPAC 2013, for all the selection indices for the characters Yield and KP. The PB index $(12.6 \%)$, as well as in the other environments, was the one of highest gain for Yield. The low gains for KP in this environment are directly influenced by the lower value of heritability (74.9\%) when compared to the other environments. The index with highest selection gain for KP was the IG, with 2.5\% (Table 1).

For the character LOD in AMB4, the index of Elston (-71.2\%), as well as in the other environment, selected the genotypes with highest SG. The MM and IG indices presented negative gains of $-27.9 \%$ and $-22.6 \%$, respectively. The PB index (-7.4\%), in spite of having negative gain, which is expected, was of low magnitude.

The index that presented the most adequate selection gains according to the goals of the breeding program for this environment was MM, with more satisfactory selection gains for the three characters of interest.
The SG obtained for Yield in AMB5, SPM 2014, were of low magnitude and low amplitude among the indices, ranging from 4.9\% for Elston to 8.1\% to PB. As well as in AMB3, CPAC 2014, the heritability was low (54.2\%), which influenced selection gains below $10 \%$ (Table 2). The OB index presented genotypes with decreases of $1 \%$ for $\mathrm{KP}$, while the other indices presented an increase of at least $5 \%$. Also, the MM index did not present increase or decrease of selection gain in relation to the LOD character. The other indices proportioned negative gains of at least $55 \%$.

In a general analysis of the mean selection gains, the PB index showed the best results for the Yield character, with low selection efficiency of genotypes for KP and occasionally with loss in the selection in relations to lodging. Differently from the PB index, the Elston index obtained the best results for KP and LOD, but with less efficiency in the selection of genotypes for Yield.

The selection indices MM and IG were the ones that made possible the most adequate selection gains in relation to the characters of interest simultaneously (Table 2). The selection gains were intermediate in comparison to the other indices; however, the three characters presented significant gains. These gains make these indices more interesting from the agronomic point of view and for purposes of enhancement in the use of genotype simultaneous selection.

Negative selection gains were obtained for days to heading (Cycle), and for the thousand seeds weight (TSW) (Table 3). The TSW is a character that contributes for the increase of grain yield [17], however, for the selected genotypes, the TSW didn't affect this character significantly.

Data related to the selection gains obtained by selection indices for agronomic characters in barley are rare. Recently, Amabile., et al. [18], used the Elston index in 30 elite genotypes of barley under irrigation, and reported gains of $14.0 \%$ for Yield and $-42.0 \%$ for LOD. However, the gains for KP were practically null $(0.45 \%)$. In this case, the null gain did not represent an obstacle, since the selection occurred in elite genotypes with the mean of the population $\mathrm{X} 0$ (mean of the original population) equal to $85 \%$ for KP, a value within the desired standards for malting barley (> $80 \%$ ) [19]. 


\begin{tabular}{|l|c|c|c|c|c|c|}
\hline $\begin{array}{l}\text { Site/ } \\
\text { Character }\end{array}$ & Yield & Class1 & TSW & Height & LOD & Cycle \\
\hline AMB1 & 4360.9 & 81.7 & 45.3 & 75.5 & 15.6 & 54.3 \\
\hline AMB2 & 5022.7 & 69.0 & 40.7 & 78.6 & 52.6 & 57.9 \\
\hline AMB3 & 5161.9 & 73.8 & 44.5 & 81.4 & 2.7 & 58.5 \\
\hline AMB4 & 6730.7 & 85.8 & 45.1 & 85.6 & 62.9 & 52.5 \\
\hline AMB5 & 6780.3 & 79.5 & 41.0 & 95.5 & 20.4 & 55.2 \\
\hline Mean & 5611.3 & 77.9 & 43.3 & 83.3 & 30.8 & 55.7 \\
\hline
\end{tabular}

\begin{tabular}{|l|l|c|c|c|c|c|}
\hline \multicolumn{2}{|c|}{} & NGD & Elston & PB & MM & GI \\
\hline \multirow{2}{*}{$\begin{array}{l}\text { Number of } \\
\text { genotype }\end{array}$} & 1 environment & 64 & 49 & 50 & 52 & 48 \\
\cline { 2 - 8 } $\begin{array}{l}\text { selected in } \\
\text { at least: }\end{array}$ & 2 environments & 48 & 32 & 32 & 25 & 30 \\
\cline { 2 - 8 } & 3 environments & 28 & 19 & 15 & 17 & 18 \\
\cline { 2 - 7 } & 4 environments & 13 & 5 & 7 & 7 & 7 \\
\cline { 2 - 7 } & 5 environments & 3 & 0 & 1 & 1 & 2 \\
\hline
\end{tabular}

Table 4: Number of genotypes selected by the selection indices simultaneously in the experimental environments.

Table 3: Mean of the 21 genotypes selected through Combined Selection (CS).

*Yield: estimated grain yield (kg.ha-1); Class1: kernel plumpness (>2.5 mm) (\%); TSW: weight of a thousand seeds (g); Height: height of the plants (cm); LOD: plant lodging (\%); Cycle: days to heading (days)

\section{Combined Selection}

The genotypes selected (21) through CS are mostly of Colombian origin, the other three genotypes are of Brazilian (the cultivar recommended for the savanna BRS 180), Canadian, and Russian origins. All genotypes have six rows of kernels and have cream colored caryopsis. The mean selection gains in CS for Yield, KP, and LOD were $4.39 \%, 8.16 \%$, and $-39.96 \%$, respectively (Table 2).

Although the selection gains were not the greatest when compared to the selection indices, the selected genotypes presented higher stability in relation to the characters used in the selection. This was because the CS was based on the five environments, reducing the environmental influence in the selection of the best genotypes. The table 4 presents the number of genotypes selected by the indices simultaneously in the different environments. It's evident the difficulty in obtaining a common number of genotypes that were selected in the five environments used, once only three genotypes were selected in the five environments.

Of the 21 CS genotypes, 18 were selected in at least three environments and 11 were selected in at least four environments. Comparatively, the four selection indices used selected from 15 to 19 genotypes in at least three environments, totaling 28 different genotypes (Table 4).

${ }^{* *}$ Elston: Elston Index (1963); PB: Pesek and Baker Index (1969); MM: Mulamba and Mock Index (1978); IG: Ideotype-genotype distance Index (2006); CS: Combined Selection;

**NDG: Number of different genotypes selected

The genotype that was selected the most was the Brazilian cultivar BRS 180, that was selected 18 times out of 20 . Other two genotypes stood out for being more stable, and were selected 16 times by the selections indices applied in the five environments. These were the genotypes MCU 3634 PI 402112 and MCU 3851 PI 402329, both with mean Yield above 6,000 kg.ha ${ }^{-1}$ and KP above 78.9\% (Table 1).

The selected genotypes presented means of Yield of 5,611 kg.ha ${ }^{-1}, \mathrm{KP}$ of $77.9 \%$, and LOD of $30.8 \%$. These values are very close to the values considered ideal for the production system of the irrigated savanna [18] (Table 3). The means of Yield for the environments 4 and 5 (above 6,700 kg.ha-1) are considered very high, since it is the mean of 21 genotypes, and the mean yield in the state of Paraná (state with the highest yield) is around 4,000 kg.ha-1 [20]. The level of LOD next to the acceptable limit (30\%) occurred mainly due to the year of 2013, when the high level in the environments 2 and 4 contributed to the increment of the levels of this character in the mean of the genotypes.

\section{Coincidence index}

The Combined Selection is the combination of the selection index of Mulamba and Mock with the Elston index. Therefore, genotypes with lodging higher than $30 \%$ and KP lower than $70 \%$ in 3 environments were discarded, making it possible to obtain high selection gains for these characters. 
Amb3 was the environment in which the highest coincidence occurred between CS and the selection of other indices, except the PB index. This was due to the high selection gains for KP and LOD that were possible to obtain in this environment, which is in line with the selection of PB that obtained high performance in the selection for Yield. Non-randomly, the Elston index presented a coincidence of $76 \%$, given its efficiency for selection of genotypes for these characters (Table 5).

\begin{tabular}{|c|c|c|c|c|c|}
\hline Site $\backslash$ Selection Index & Elston & PB & MM & IG & Mean \\
\hline Amb1 & 0.62 & 0.33 & 0.57 & 0.62 & 0.536 \\
\hline Amb2 & 0.38 & 0.38 & 0.48 & 0.48 & 0.429 \\
\hline Amb3 & 0.76 & 0.52 & 0.71 & 0.62 & 0.655 \\
\hline Amb4 & 0.43 & 0.57 & 0.62 & 0.62 & 0.560 \\
\hline Amb5 & 0.67 & 0.62 & 0.48 & 0.71 & 0.619 \\
\hline Mean & 0.571 & 0.486 & 0.571 & 0.610 & \\
\hline
\end{tabular}

Table 5: Coincidence index between the selection indices and the Combined Selection.

*Elston: Elston Index (1963); PB: Pesek and Baker Index (1969); MM: Mulamba and Mock Index (1978); IG: Ideotype-genotype distance Index (2006); CS: Combined Selection.

Environment 2 obtained the lowest mean of coincidence with CS among the environments, probably due to the low selection gains in relation to LOD obtained in this environment by all selection indices when compared to other environments (Table 5).

The ideotype-genotype selection index (0.61) presented highest coincidence with the CS (Table 5). Like the MM index, the IG index obtained intermediate gains for the three characters of interest. This greater coincidence between IG and CS is very interesting for malting barley breeding, since intermediate gains in all traits of interest result in more attractive genotypes for both the farmer and the brewing industry.

\section{Conclusions}

The Weight-free and Parameter-free and Desired Genetic Gain indices were not adequate to simultaneously select the three characteristics of interest for barley.

The selection indices of Mulamba and Mock and of the Ideotypegenotype distance were considered more interesting for simulta- neous selection due to selection gains of satisfactory magnitude for the three characteristics of interest.

Based on the selection of genotypes for each index within the environments, it was more efficient to select the most stable materials, since they obtained a higher frequency of selection among the other indexes.

\section{Bibliography}

1. NOGUEIRA A., et al. "Análise de trilha e correlações entre caracteres em soja cultivada em duas épocas de semeadura". Bioscience Journal 28.6 (2012): 877-888.

2. CRUZ C D. "Genes: a software package for analysis in experimental statistics and quantitative genetics". Acta Scientiarum Agronomy 35.3 (2013): 271- 276.

3. AMABILE R F and FALEIRO F G. "A cevada irrigada no Cerrado: estado da arte, recursos genéticos e melhoramento" Embrapa (2014): 127.

4. SAYD RM. "Variabilidade, parâmetros genéticos e caracterização agronômica e molecular de genótipos de cevada nua (hordeum vulgare l. Var. nudum hook. F.) sob irrigação no Cerrado". Dissertação (Mestrado em Agronomia) - Universidade de Brasília, Brasília (2014): 83.

5. AMABILE R., et al. "Estimation of genetic parameters, phenotypic, genotypic and environmental correlations on barley (Hordeum vulgare L.) grown under irrigation conditions in the Brazilian savanna". Interciencia 40 (2015): 255-262.

6. SAYD R M., et al. "Genetic parameters and agronomic characterization of high productivity irrigated barley accessions in the Brazilian Savanna". Pesquisa Agropecuária Brasileira 52.1 (2017): 84-94.

7. SAYD RM., et al. "Genetic variability of hull-less barley accessions based on molecular and quantitative data". Pesquisa Agropecuaria Brasileira 50.2 (2015):160-167.

8. REZENDE J C., et al. "Genetic progress in coffee progenies by different selection criteria”. Coffee Science 9.3 (2014): 347353.

9. CRUZ C D and CARNEIRO P C S. "Modelos biométricos aplicados ao melhoramento genético". Universidade Federal de Viçosa (2006): 585. 
10. SMITH H F. "A discriminant function for plant selection". Annals of Eugenics 7 (1936): 240-250.

11. HAZEL L N. "The genetic basis for constructing selection indexes". Genetics 28 (1943): 476-490.

12. PESEK J and BAKER R J. "Desired improvement in relation to selected indices". Canadian Journal of Plant Sciences. 49 (1969): 803-804.

13. ELSTON R C. "A weight-free index for the purpose of ranking or selection with respect to several traits at a time". Biometrics. 19.1 (1963): 85-97.

14. GARCIA A A F. "Índice para a seleção de cultivares. Piracicaba: ESALQ/USP". Esalq - USP (1998): 112.

15. MULAMBA N N and MOCK J J. "Improvement of yield potential of the Eto Blanco maize (Zea mays L.) population by breeding for plant traits". Journal of Cytology 7 (1978): 40-51.

16. CRUZ C D. "Programa Genes: biometria. Viçosa” UFV (2006): 382.

17. RASSMUSON D C. "An evaluation of ideotype breeding". Crop Science. 27.6 (1987): 1140-1146.

18. AMABILE R F., et al. "Genetic diversity of irrigated barley based on molecular and quantitative data and on malting quality". Pesquisa Agropecuária Brasileira 48.7 (2013): 748-756.

19. BRASIL. "Ministério da Agricultura e Abastecimento. Portaria". Brasília (1996): 24751-24752.

20. CONAB. “Acomp. safra bras. Grãos”. Brasília 9 (2016): 1-178

Volume 3 Issue 9 September 2019

(C) All rights are reserved by Ricardo Meneses Sayd., et

al. 